\title{
A apocalipse dos palhaços e os palhaços assustadores
}

\author{
Clown apocalypse and the scary clown
}

Fabio Dal Gallo ${ }^{1}$

Professor Adjunto IV da Escola de Teatro da UFBA e docente do Programa de PósGraduação em Artes Cênicas da UFBA.

ORCID: http://orcid.org/ 0000-0002-3664-3118 .

Contato:

fabio.gallo@ufba.br

\section{ABSTRACT}

This article examines the scary clowns and what is defined as the apocalypse of clowns. By reporting the recent events of this phenomenon some possible relations are analyzed between the clown's mask and the harlequin's mask that contain elements traced back to the image of the medieval demon. It is showed that the clown is recognized nowadays by its technique, that the scary clowns are distinct from the clown itself and that they damage socially and artistically the image of professional clowns.

Keywords: Clown. Scare. Mask. 
A partir de meados de agosto de 2016, iniciou-se um fenômeno singular que se difundiu rapidamente segundo o qual um crescente número de sujeitos vai às ruas usando máscara e figurino de palhaço com a intenção de assustar as pessoas que transitam em lugares públicos. Essas ações que, no conjunto, foram denominadas de "apocalipse dos palhaços", envolvem personagens que são chamados de palhaços assustadores, os quais chegaram a criar problemas de ordem pública em vários países do mundo e a realizar atos que incluem casos de violência e agressões físicas.

As ações realizadas pelos palhaços assustadores se tornaram verdadeiros casos de segurança e preocuparam órgãos públicos pelo fato de, em apenas dois meses, ocorrerem registros de centenas de casos, em diferentes contextos. Alguns desses palhaços assustadores chegaram a ser presos com a acusação de promoverem ações de terrorismo.

De acordo com as notícias veiculadas recentemente nos meios de comunicação de massa, esta moda começou nos Estados Unidos e se espalhou rapidamente pelo Canadá e Inglaterra, havendo casos que foram registrados não somente na América do Norte e Europa, mas também aqui na América do Sul, o que inclui o Brasil. As cenas acontecem principalmente em centros urbanos, mas há casos de apresentações registrados também nas regiões rurais que contaram, entre outras respostas violentas das vítimas atingidas por estas abordagens por parte de palhaços assustadores, com ações não racionais. Aconteceram casos de pessoas, por exemplo, que se "defenderam" destes palhaços com armas de fogo, ao passo em que outras pessoas se organizaram em grupos e improvisaram como "caçadores de palhaços", proporcionando situações de conflito não apenas com os sujeitos que alimentam este novo fenômeno, mas também com artistas profissionais que atuam em espaços públicos usando a técnica do palhaço como parte constitutiva do espetáculo apresentado, o qual se insere numa atividade que é típica da tradição do teatro de rua.

Deste modo, foram surgindo casos de um tipo de psicose denominada de clown hysteria (histerias de palhaços), nos quais, em casos agudos, o medo pode até evoluir para uma patologia clínica chamada especificamente de "coulrofobia", sendo esta uma forma de fobia vinculada à figura do palhaço.

Um exemplo claro de histeria de palhaços, de acordo com notícias amplamente divulgadas ${ }^{2}$ no começo de outubro de 2016, foi um fato que aconteceu na cidade de Bardstown, Estados Unidos, quando um homem chegou a disparar tiros para o alto com uma carabina AR-15 após ter sido avisado pela sua esposa sobre a presença desses palhaços assustadores na rua próxima de casa. Esse fato é extremamente preocupante, especialmente
Ver: http://g1.globo.com/ mundo/noticia/2016/10/o-que-esta-por-tras-da-onda-de-palhacos-assustadores-nos-eua.html acesso em 16 de outubro de 2016. 
porque essa figura não era de um desses sujeitos que alimentam o apocalipse dos palhaços, mas apenas uma mulher que estava passeando de madrugada com o seu cachorro.

As consequências do aumento dos palhaços assustadores e do posicionamento da mídia e da sociedade em relação ao clown de maneira generalizada chegaram até a incentivar uma multinacional de fast food a limitar as aparições de seu mascote que, há décadas, é representado pela figura de um palhaço.

Outra consequência advinda com o fenômeno dos palhaços assustadores foi o fato de a sociedade civil evitar o contato com a figura do palhaço, promovendo inclusive o distanciamento dessa figura dos eventos onde, geralmente, haviam constantes contratações, havendo, assim, um número considerável de cancelamentos de espetáculos que envolviam palhaços, isto sem considerar que muitos profissionais da área até foram chamados deliberadamente de assassinos, inclusive por crianças, ao transitar caracterizados pela rua.

A velocidade com a qual o fenômeno do apocalipse dos palhaços se espalhou, em conjunto com a resposta da sociedade que começou a tratar de maneira negativa e preconceituosa a figura do palhaço, independentemente de quem seja esse sujeito ou a sua relação deste com os palhaços assustadores, preocupou determinantemente a classe artística que trabalha com palhaço, a qual chegou a realizar manifestações no Brasil.

No Estado de São Paulo, os artistas foram às ruas para promover a ideia do "palhaço do bem" e, se posicionando contra os palhaços assustadores, esses profissionais das artes cênicas foram para as ruas mostrando panfletos e cartazes que transmitiam mensagens de protesto como, por exemplo, "palhaço não é assassino, palhaço é alegria" ou "palhaço não é assassino, palhaço é amor". Manifestações deste tipo aconteceram no mês de outubro de 2016 não apenas no Brasil, mas também em outros diferentes países, como, por exemplo, no México.

O fenômeno dos palhaços assustadores como performance cênica nasceu na Itália no ano de 2013 e foi idealizado por um jovem de quase trinta anos de idade chamado Matteo Moroni, que é conhecido por ter fundado a produtora "DM Pranks", que atua no campo do audiovisual produzindo vídeos que envolvem, de modo específicos, os palhaços assustadores.

A partir daquele ano, Moroni começou a se vestir e se maquiar de palhaço malvado e a gravar uma série de vídeos de pegadinhas que foram publicadas no YouTube. Esses vídeos, gravados com câmeras previamente colocadas em lugares escondidos, focam as pessoas que transitam pelo local e que, inesperadamente, são surpreendidas por uma cena de agressão ou de crime encenada por um desses palhaços. Esses palhaços, que naquele momento estão ocupados em realizar ações fictícias de cunho violento, ao 
ter contato visual com o(s) transeunte(s), gravam a reação desses sujeitos, chegando até a persegui-los, de modo a conseguir gravar uma boa cena da reação, foco de toda a encenação.

Moroni tem milhões de seguidores que assistem aos seus vídeos em todo o mundo, os quais foram gravados principalmente na Itália e, mais recentemente, nos Estados Unidos, onde exatamente este fenômeno do apocalipse dos palhaços explodiu.

De acordo com indicações de um conjunto de informações de diferentes sites, o idealizador dessas performances, porém, busca não surpreender pessoas aleatoriamente, mas antes, seguir uma lista de regras sobre o tipo de público a ser atingido. Nesta lista haveria indicações, por exemplo, de que as ações com os palhaços assustadores não devem ser direcionadas a mulheres sozinhas, crianças e idosos; além disso, estaria escrito sobre a necessidade da colocação de placas para alertar sobre a atividade que está sendo realizada, de modo a evitar, também, o trânsito de pessoas que usam marca-passo.

No entanto, aqueles que se emulam como palhaços assustadores e alimentam o apocalipse dos palhaços, ao que parece, não seguem um conjunto de normas de ética e, por isso, acabam criando situações que, como já anunciado, se tornaram problemas até de segurança pública. O primeiro caso deste tipo denunciado às autoridades aconteceu na metade de agosto de 2016, na cidade de Greenville, no Estado da Carolina do Sul, nos Estados Unidos, quando um grupo de palhaços armados com facas tentou atrair um grupo de crianças que passavam na rua para dentro de um bosque.

Todavia, é interessante marcar que o fator "novidade" dessas cenas reside principalmente em seu caráter performativo, pois a figura do palhaço é utilizada como protagonista de uma produção audiovisual que enfatiza o lado obscuro do próprio palhaço, de modo que as cenas, quando gravadas, podem ser comparadas ao que acontece em um reality show, no qual as pessoas que participam realizam ações normais e espontâneas de acordo com as situações vivenciadas, não sendo um personagem criado para uma situação ficcional, mas que se torna parte, posteriormente, de um acontecimento espetacular.

Assim, o fenômeno do apocalipse dos palhaços se constitui na associação de um tipo específico de produção audiovisual que envolve um tipo particular de palhaço com o fato de um amplo número de pessoas, em diversos países, estarem realizando ações que imitam, de certa forma, o que é divulgado nesses vídeos.

Vale destacar, porém, que não há novidade em relação aos protagonistas envolvidos neste tipo de produção, pois, ao longo dos anos, é notável a existência de filmes e outros produtos cinematográficos que focaram suas narrativas e dramaturgias em personagens que são chamados de palhaços assassinos. 
No cinema, o personagem do palhaço com ser macabro já foi amplamente utilizado e investigado, principalmente em obras de longa-metragem e minisséries. Entre os filmes produzidos podemos citar como exemplos: "Drive-thru: fast food da morte", de 2007, no qual uma pessoa com máscara de palhaço realiza assassinatos nas proximidades de uma lanchonete; "Gacy", de 2003, que conta uma história verídica de um assassino serial que, caracterizado de palhaço, matava pessoas e enterrava os corpos das vítimas em seu quintal; "O palhaço assassino" - título original "The clown at midnight" - que é um filme de 1998 no qual o protagonista é um palhaço que aterroriza as pessoas em um teatro onde, anos antes, teria ocorrido o assassinato de uma diva; "Clownhouse", de 1989, que narra a história de três doentes mentais que escapam de uma clínica psiquiátrica, matam os palhaços de um circo e, após roubar os figurinos desses palhaços, semeiam o terror por toda a cidade onde o circo está instalado.

Decerto, um dos filmes de terror mais conhecidos que tem como protagonista a figura do palhaço assassino é o "It", de 1990, que foi um dos grandes divulgadores deste tipo de olhar sobre o palhaço. Vale citar também uma das mais antigas produções cinematográficas que conta com a presença dos palhaços assassinos e assustadores como protagonistas, o filme intitulado "Os palhaços assassinos do espaço sideral", de 1988, que conta a chegada de um óvni na terra que se converte em uma lona de circo e tem os palhaços assassinos que chegaram diretamente do espaço.

O elenco dos filmes citados aqui conta com apenas uma parte das muitas sequências de imagens já produzidas e apresentadas ao grande público ao longo de quase três décadas, que tem os palhaços assassinos como protagonistas. Atualmente, ainda há produções em andamento como, por exemplo, o novo filme "It", que será lançado em 2017 e que já está, atualmente, fazendo propaganda do seu lançamento.

Após descrever a trajetória do recente fenômeno do apocalipse dos palhaços e dos palhaços assustadores e sua relação com o âmbito da ação performática interligada com a linguagem audiovisual, questiona-se: porque, entre tantas figuras e máscaras da tradição teatral e circense, assim como outros exemplos de figuras folclóricas que podem representar elementos e instintos negativos e violentos do ser humano, o palhaço se destacou com a figura foco dessa ocorrência?

Se formos observar a literatura específica sobre a técnica do palhaço, especialmente no que se refere ao processo de formação e iniciação nesta arte, nota-se que a grande maioria dos autores, entre os quais pode-se destacar Farneti (2004), indicam frequentemente a existência de uma "filosofia do palhaço" e de uma "psicologia do clown".

Elaborando uma breve consideração sobre esses termos, 
pode-se marcar que os princípios daquilo que Farneti (2004) chama de "filosofia do palhaço" são especialmente os valores do palhaço como ser. A autora indica que ele é um emblema de simplicidade, de genuinidade, de inocência, de auto-ironia, de capacidade mascarada e dissimulada. Farneti (2004) destaca os aspectos que estão evidentes em publicações que tratam sobre o palhaço, baseando-se, principalmente, nos livros de Galante Garrone (1980) e Dário Fó (2009).

A máscara do clown, que frequentemente é associada ao nariz vermelho e a uma maquiagem característica, ainda acordo com Farneti (2004), é apropriada, pois permite esconder o próprio ego e medos, deixando espaço para a liberdade de brincar com as partes menos aceitas em si mesmo. Os princípios dessa "filosofia do palhaço" se fundamentam, portanto, na possibilidade de expressão, especialmente por meio do corpo, incluindo ações que exigem a aceitação de derrotas, aprender a se sentir pequeno e sem capacidades, aprender a expressar as emoções, utilizar gestos e objetos de maneira não convencional, fazer do jogo e do espontâneo o centro da própria ação, observar com maravilha como se tudo fosse sempre novo e diferente - tudo isso considerando as diferenças como um aspecto de riqueza cultural.

Jara (2010), no capítulo intitulado "Filosofia e psicologia do clown", destaca a importância social do palhaço pelo fato de ele divertir, entreter e fazer rir como finalidade. O autor sublinha que os palhaços transmitem uma imagem global positiva como pessoa, e afirma que "não aceitaríamos um clown malvado, grosseiro, ou antipático, porque isso impediria a familiaridade e a identificação" (JARA 2010, p. 45). Nesta parte de sua publicação, Jara (2010) trata ainda sobre a importância da risoterapia e frisa a aproximação do palhaço com a infância, sublinhando que o clown, porém, não é uma criança, mas se comporta como tal sem esquecer a sua idade.

A partir deste aspecto, pode-se observar que apesar de ser pertinente a associação do palhaço com valores e qualidades positivas, Jara (2010) afirma também que os palhaços oferecem um leque de emoções que formam parte da essência do ser humano e que refletem com certeza o amor e a alegria, mas também a dor, a tristeza e a raiva, entre outras emoções.

É importante constatar que os palhaços assustadores aqui tratados utilizam quase em sua totalidade uma caracterização que reconduz à figura do palhaço do circo moderno, um tipo de circo que surgiu a partir do final do século XVIII, o qual se destaca pela frequente utilização do nariz vermelho, pela indumentária exagerada em seu tamanho e cores, maquiagem carregada que amplia as feições do rosto e do corpo como um todo.

Não se pode esquecer também que a figura do palhaço do circo moderno tem entre seus antecessores mais imediatos os 
tipos cômicos da Comédia Dell'Arte que, usavam máscaras como a do Arlequim e do Polichinelo. O arlequim, em particular, que recebe o seu nome de Hellequin, é, de acordo com Toschi (1976), um tipo de diabo que, nas representações medievais, incorpora aspectos grotescos do diabo medieval, e o que mais aproxima este tipo de diabo ao tipo cômico desta máscara é principalmente a sua risada.

Possivelmente, é por esta ligação e herança cultural com a mascara e a risada do arlequim e esta aproximação com o diabo medieval que é comum encontrar o termo palhaço associado não apenas à ingenuidade, à infância e a qualidades positivas, mas também a conceitos que se aproximam do horror, do terror, do mal e do macabro; dito isto, pode-se pensar que houve influência desta herança cultural e da própria máscara no surgimento dessas vertentes que levaram ao fenômeno dos palhaço assustadores. Todavia, há um ponto relevante frequentemente encontrado na literatura de diferentes autores que tratam sobre o palhaço, entre os quais se podem destacar as considerações de Farneti (2004), que indica que o palhaço se constitui em primeiro lugar a partir da ação cênica.

Assim sendo, é a ação e a técnica utilizada que distingue, em primeiro lugar, o que é um palhaço. Ao discorrer sobre este tema no artigo "História e Rumos da Máscara Clownesca" (GALLO, 2012), foi possível demonstrar que, apesar de em algum período histórico a caracterização identificar a prática do palhaço, entre os quais se inclui também o palhaço do circo moderno, hoje em dia não é mais a indumentária e a maquiagem que identificam este personagem, sendo mais relevante a utilização do que se pode definir como técnica do palhaço na composição cênica, a qual envolve, entre outros aspectos, para determinar o fazer desta personagem em cena: 1) a criação de um corpo cômico; 2) o direcionamento do foco; 3) a utilização recorrente da triangulação com o público; 4) o tempo cômico; e 5) a dramaturgia e a ação cênica, baseada no que pode ser chamado de "lógica do palhaço", com a presença de uma possível "filosofia e psicologia do palhaço".

Os elementos relacionados com a técnica do palhaço não estão presentes nas atividades realizadas pelos palhaços assustadores, pois estes utilizam meramente uma caracterização que se aproxima especificamente quanto ao vestuário e à maquiagem do palhaço do circo moderno, induzindo assim a uma identificação dos palhaços com os palhaços assustadores.

Por tal razão, pode-se dizer que os que são denominados de palhaços assustadores, que fomentaram o apocalipse dos palhaços e contribuem para o surgimento da histeria do palhaço e a coulrofobia, não são reconduzíveis ao palhaço, pois estes não agem como tal, principalmente no que se refere às questões técnicas e artísticas. 
O fenômeno do apocalipse dos palhaços trata-se de um modismo que, possivelmente, se baseia numa revisitação de vestígios ligados à herança cultural que permeia a figura do palhaço, com a criação equivocada de uma associação entre o termo palhaço e os palhaços assustadores, sendo essa aproximação fundamentada apenas na ressignificação de elementos da visualidade do palhaço do circo moderno para fomentar, assim, um olhar pernicioso sobre o trabalho do palhaço que atua no campo da prática das artes cênicas. 


\section{REFERENNCIAS}

FARNETI, Alessandra. La maschera più piccola del mondo. Aspetti psicologici della clownerie. Bologna: Perdisa, 2004. FO, Dario. Manuale Minimo dell'attore. Torino: Einaudi, 2009. GALANTE GARRONE, Alessandra. Alla ricerca del proprio clown. Firenze: La Casa Usher, 1980.

TOSCHI, Paolo. Le origini del teatro italiano; origini rituali della rappresentazione popolare in Italia. Torino: Boringhieri, 1976. JARA, Jesús. El Clown un navegante de las emociones. Sevilla: Proexdra, 2010.

GALLO, Fabio, Dal. História e Rumos da Máscara Clownesca. In: Aglae Joice; Telles Narciso; Campos Vilma (Orgs). Teatro-MascaraRitual. Uberlândia: Aline Editora, 2012. 